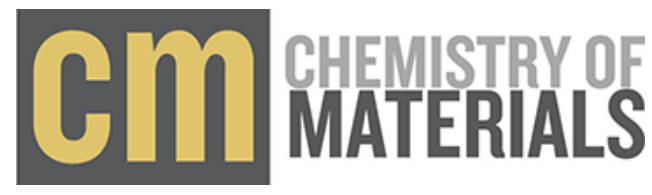

Article

Subscriber access provided by Basel University Library

\section{ACS Publications}




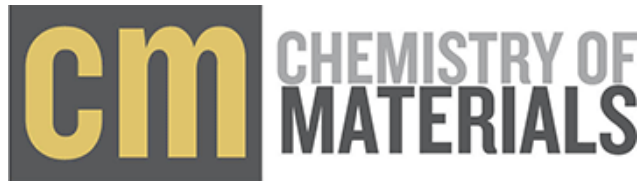

Genetically encoded stimuli-responsive cytoprotective hydrogel

Subscriber access provided by Basel University Library capsules for single cells provide novel genotype-phenotype linkage

Rosario Vanella, Alfred Bazin, Duy Tien Ta, and Michael A. Nash

\section{ACS Publications}




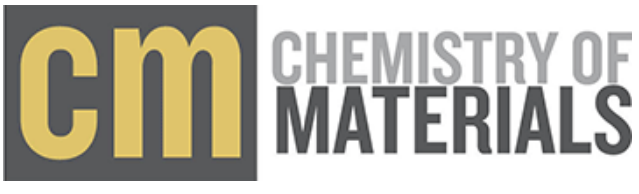

Chem. Mater., Just Accepted Manuscript • DOI: 10.1021/acs.chemmater.8b04348 • Publication Date (Web): 09 Jan 2019

Downloaded from http://pubs.acs.org on January 17, 2019

\section{ACS Publications}




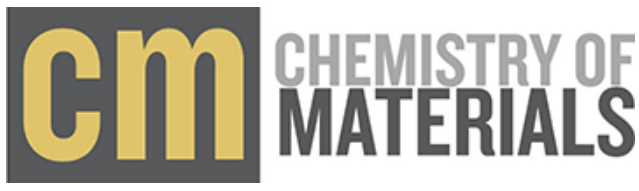

Just Accepted

Subscriber access provided by Basel University Library

"Just Accepted" manuscripts have been peer-reviewed and accepted for publication. They are posted online prior to technical editing, formatting for publication and author proofing. The American Chemical

\section{ACS Publications}


Society provides "Just Accepted" as a service to the research community to expedite the dissemination | of scientific material as soon as possible after acceptance. "Just Accepted" manuscripts appear in full in PDF format accompanied by an HTML abstract. "Just Accepted" manuscripts have been fully peer reviewed, but should not be considered the official version of record. They are citable by the

\section{ACS Publications}




\section{MAEATERYALIS}

Digital Object Identifier (DOI®). "Just Accepted" is an optional service offered to authors. Therefore, the "Just Accepted" Web site may not include all articles that will be published in the journal. After

a manuscript is technically edited and formatted, it will be removed from the "Just Accepted" Web site and published as an ASAP article. Note that technical editing may introduce minor changes

\section{ACS Publications}




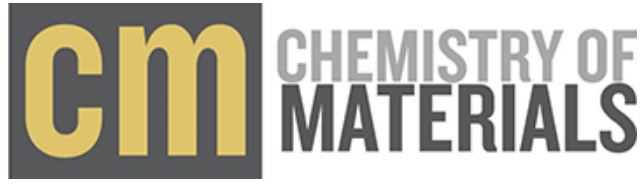

to the manuscript text and/or graphics which could affect content, and all legal disclaimers and
ethical guidelines that apply to the journal pertain. ACS cannot be held responsible for errors or consequences arising from the use of information contained in these "Just Accepted" manuscripts.

\section{ACS Publications}


A
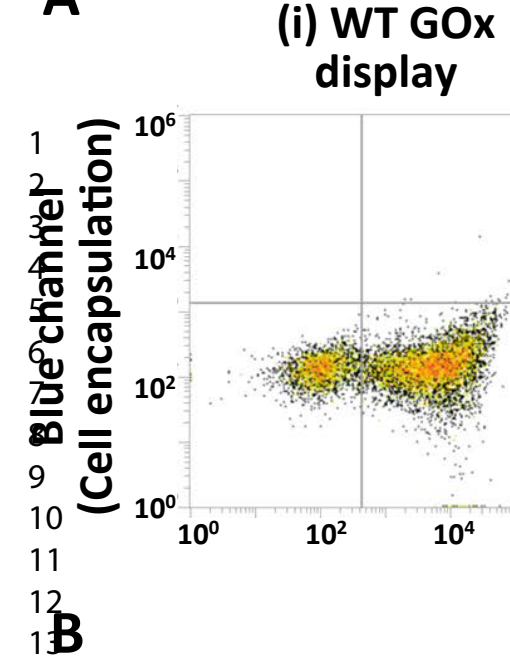

14

15

16

17

18

19

20

21

22

23

24

25

26

27

28

29 encapsulation

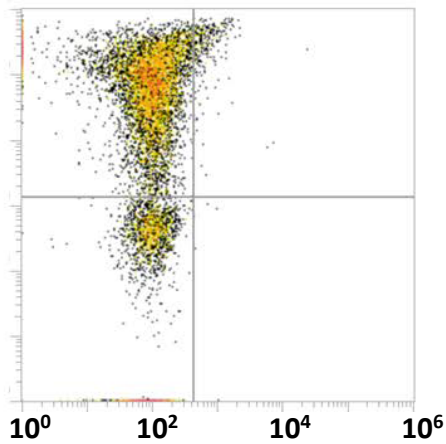

(iii) WT GOx dis;playof 23 \& encapsulation

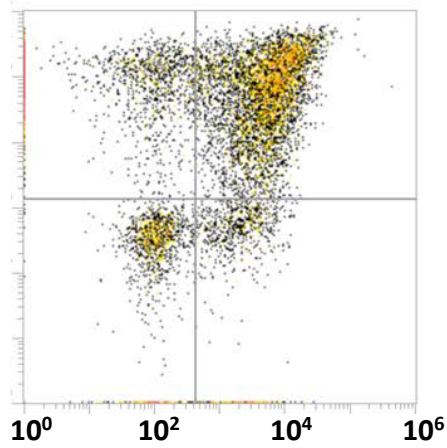

Yellow channel (GOx display)

\begin{tabular}{|ll|}
\hline $\begin{array}{l}\text { Yeast mixture } \\
\text { (\% GOx-positive } \\
\text { cells) }\end{array}$ & $\begin{array}{l}\text { \# of encapsulated } \\
\text { cells out of } \\
10^{\prime} 000\end{array}$ \\
\hline $100 \%$ & 5923 \\
$75 \%$ & 3980 \\
$50 \%$ & 2890 \\
$25 \%$ & 1368 \\
$10 \%$ & 463 \\
$1 \%$ & 65 \\
$0 \%$ & 15 \\
\hline
\end{tabular}

25\% GOx wild type cells

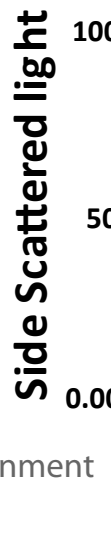

1368 events

$10^{\circ}$

Blue channel (Cell encapsulation) 
$A_{700207} 23=B$
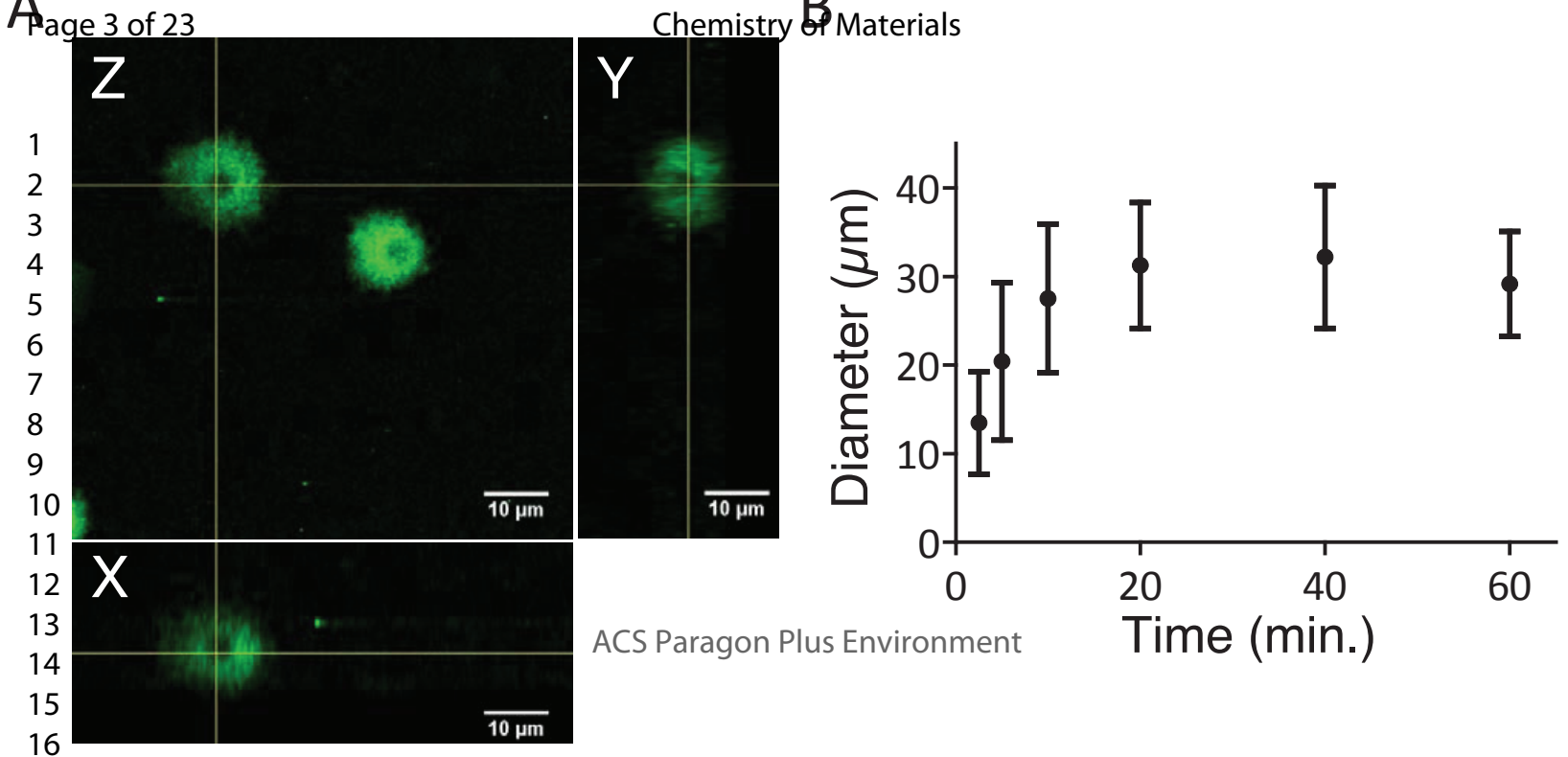

ACS Paragon Plus Environment Time (min.) 
1

2

3

4

5

6

7

8

9

10

$5 \mu \mathrm{m}$
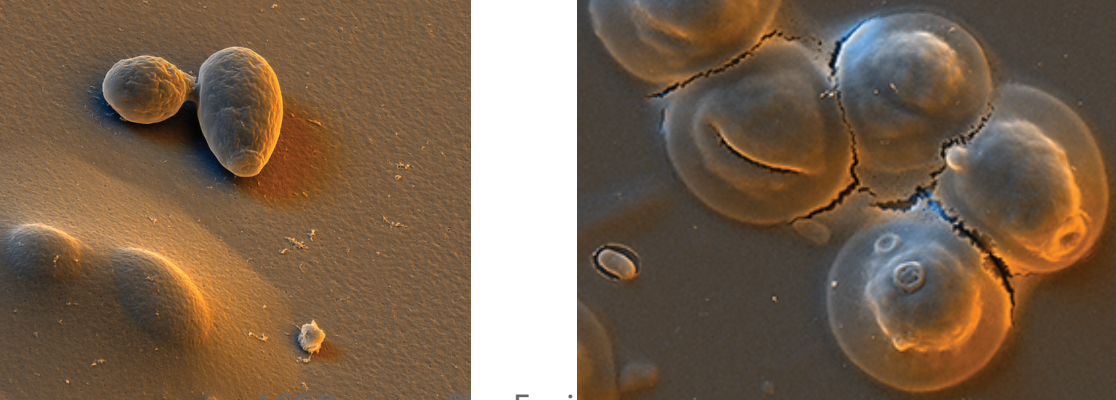

us Envi onment $10 \mu \mathrm{m}$ 

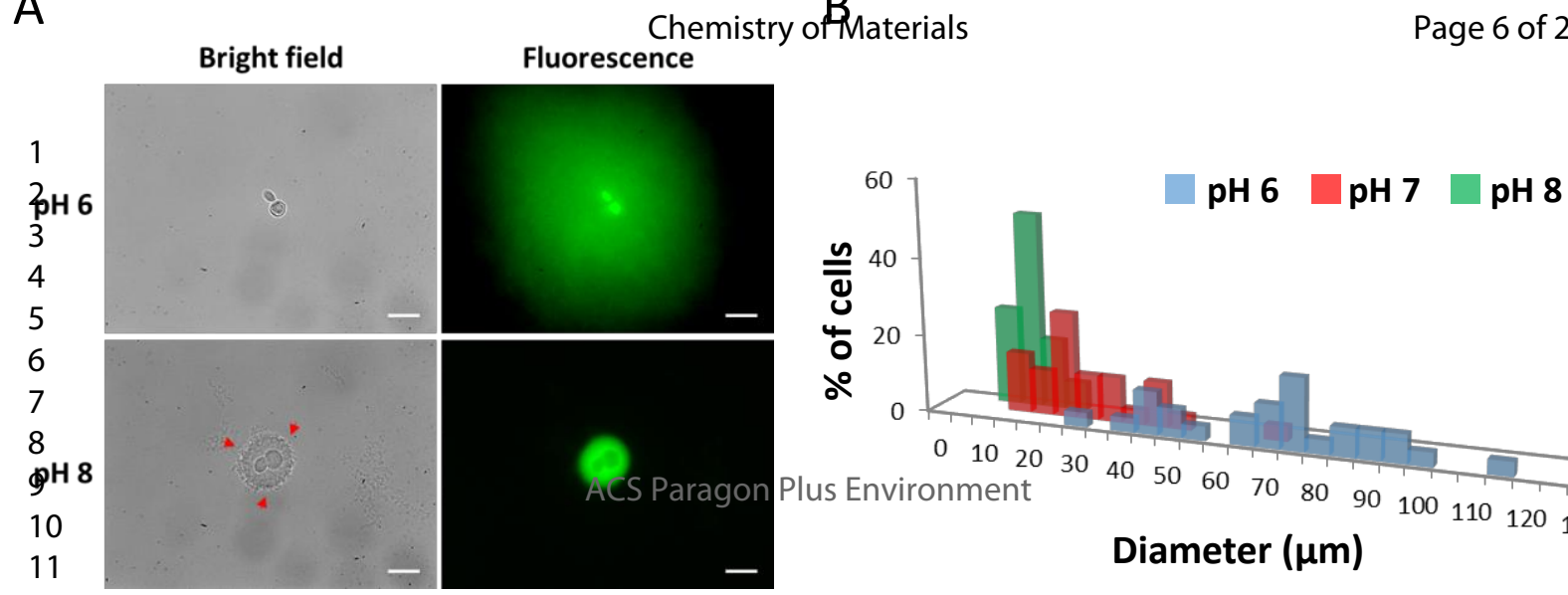
12 


\title{
Genetically encoded stimuli-responsive cytoprotective hydrogel capsules for single cells provide novel genotype-phenotype linkage
}

\author{
Rosario Vanella ${ }^{1,2}$, Alfred Bazin ${ }^{1,2,3}$, Duy Tien Ta ${ }^{1,2}$, and Michael A. Nash ${ }^{1,2 *}$ \\ ${ }^{1}$ Department of Chemistry, University of Basel, 4058 Basel, Switzerland. \\ ${ }^{2}$ Department of Biosystems Science and Engineering, ETH Zurich, 4058 Basel, Switzerland. \\ ${ }^{3}$ European School of Chemistry, Polymers and Materials, University of Strasbourg, 67087 Strasbourg, \\ France.
}

*Correspondence to michael.nash@unibas.ch

\begin{abstract}
Modification of cell surfaces with synthetic polymers is a promising approach for regulating cellular behavior. Here we describe a genetically controlled strategy for selectively encapsulating single yeast cells in synthetic microniches comprised of cross-linked phenol-modified alginate and chitosan hydrogel capsules. Our system links inducible gene expression with enzyme-mediated hydrogel polymerization and provides a novel genotype-phenotype linkage whereby only cells carrying a requisite gene encoding a flavin adenine dinucleotide (FAD)-dependent oxidoreductase undergo autonomous enzyme-mediated surface polymerization resulting in formation of hydrogel capsules. The composition of the hydrogel capsules is highly tunable and the capsule sizes are $\mathrm{pH}$-responsive, allowing for control of capsule porosity and shell diameters over a range of 15-80 $\mu \mathrm{m}$. The hydrogel capsules prevent extracellular proteins from reaching the cell surface, thereby conferring cellular immunity to lytic enzyme cocktails and rendering the hydrogel capsules cytoprotective against osmotic shock. We demonstrate the utility of this genetically controlled artificial hydrogel-encapsulated cell phenotype by isolating and enriching uniform eukaryotic cell lineages from genetically heterogeneous cell mixtures at $95-100 \%$ efficiency. The encapsulated cells remained viable and were capable of dividing and breaking free from their hydrogel capsules, allowing further propagation of selected cells. Our bottom-up approach to cellular compartmentalization links inducible intracellular genetic components with an artificial extracellular matrix that resists enzymatic lysis and mediates communication with the surrounding environment through a size-tunable and permeable hydrogel capsule.
\end{abstract}




\section{Introduction}

Compartmentalization is a defining feature of living systems. Cells, tissues and organs all exhibit an extraordinary degree of spatial segregation in form and function which is necessary for carrying out the daily activities of life. In an effort to advance synthetic biological systems, research has focused on developing compartmentalization strategies that function at the molecular-to-cellular length scales ${ }^{1-6}$. Specifically, encapsulation of individual cells inside synthetic conformal hydrogels ${ }^{7-9}$ has attracted significant attention. The ability of conformal synthetic hydrogels to serve as optical labels, act as steric protective layers, and separate distinct cell types make these systems potentially useful for rare cell isolation and in vivo cellular therapies ${ }^{10,11}$.

Several early demonstrations of cellular encapsulation technology utilized formation of multicellular aggregates on the scale of $0.1-1 \mathrm{~mm}$ by relying on self-assembly of oppositely charged polyelectrolyte chains ${ }^{12,13}$ or incorporation of cells in agarose emulsions ${ }^{14}$. Polymerization-based approaches have further been developed which rely on cross-linking polymer materials from monomeric precursor solutions ${ }^{15-21}$. Photoinitiators have also been conjugated to biomolecules (e.g., antibodies) ${ }^{22}$ which specifically recognize target cells and generate free radicals upon light exposure. In such systems, target cells within a heterogeneous mixture can be selectively encapsulated by photo-initiated polymerization in the presence of monomers.

Enzymatic initiation systems for cellular encapsulation have also been demonstrated in several formats. For example, peroxidase-mediated dityrosine cross-coupling has been used to form hydrogels capsules around cells ${ }^{23-25}$. Sakai, Taya and co-workers demonstrated single-cell encapsulation based on horseraddish peroxidase (HRP)-mediated polymerization, as well as cascade reactions involving glucose oxidase (GOx) as a source of $\mathrm{H}_{2} \mathrm{O}_{2}$ to feed HRP-mediated reactions ${ }^{18,26,27}$. Inspired by this prior work, we sought here to utilize the GOx/HRP cascade for cross-linking hydrogels, but instead of supplying the enzymes to cells from the outside, we sought to develop a system in which the polymerization enzyme itself was genetically encoded in DNA plasmids carried by the cells. Gene induction and expression inside the cells then resulted in protein synthesis of the enzymatic initiators. Using secretion and display pathways in yeast, the initiator enzymes were then displayed on the outer cell wall and able to trigger enzymatic crosslinking of hydrogels shells resulting in cell encapsulation. These new innovations rely on the presence or absence of a single copy of a gene inside the cell to produce single-cell hydrogel capsules which serve as an artificial phenotype linked with the genotype of the cells. Our approach which relies on synthesis of enzymatic initiators inside the cells is referred to as 'bottom-up' encapsulation, and can be contrasted with the prior systems in which cells were extrinsically labelled with initiator compounds that triggered polymerization/encapsulation reactions, which we refer to as 'top-down' encapsulation systems ${ }^{28-31}$. An additional level of novelty in the current work is the first demonstration of chitosan capsules for single-cell 
encapsulation via an enzyme-mediated process, which is significant because the chitosan shells are size tunable depending on the $\mathrm{pH}$ of the surrounding media.

Pitzler et $\mathrm{al}^{32}$ also demonstrated a bottom-up polymerization system where expression of glucose phosphatase was coupled with Fenton chemistry to produce hydrogels at the E. coli surface, however in that prior work the hydrogel served as a fluorescent tag and was not shown to be uniform, robust or sufficiently thick to confer altered physical properties to cells that could be used for large scale selections. Our hydrogels in contrast form uniform capsules, are physically robust, tens of microns thick, and capable of protecting cells from osmotic lysis. The shells shown here further impart new physico-chemical properties such as significantly increased cell size and pH-responsiveness that enable new cell isolation procedures (e.g., sizebased filtration) that are useful for various synthetic biology applications. Our strategy therefore represents the first cell encapsulation system that utilizes inducible genes to create well-defined cytoprotective hydrogel enclosures around live eukaryotic cells. Such an approach has significant potential in cell screening, cellbased therapy and directed evolution applications where the cytoprotection and/or isolation of specific cell genotypes are of high interest.

\section{Experimental Section}

Materials. All the chemicals used in this work were purchased from Sigma Aldrich if not otherwise specified. The primary and secondary antibody were purchased from Thermo Fisher Scientific. Restriction enzymes were bought from New England Biolabs. Sodium Alginate (Viscosity 1\%: 100 - 200 mPa.s) was purchased from Duchefa Biochemie. Zymolyase 100T was purchased from Roth.

Preparation of fluorescent alginate and chitosan with phenol groups. Alginate and chitosan with phenol moieties and fluorescein were prepared through carbodiimide activation chemistry ${ }^{33}$. Sodium alginate (avg. $\mathrm{M}_{\mathrm{W}} 70,000 \mathrm{Da}$ ) was dissolved in $50 \mathrm{mM}$ MES buffer $\mathrm{pH} 6$ at a final concentration of $10 \mathrm{mg} / \mathrm{mL}$. After the alginate was completely dissolved, tyramine hydrochloride, NHS and EDC were added to the sodium alginate solution at $7,1.2,3.9 \mathrm{mg} / \mathrm{mL}$ respectively. Finally, 6-aminofluorescein was added to a final concentration of $0.25 \mathrm{mg} / \mathrm{mL}$. Chitosan (avg. $\mathrm{M}_{\mathrm{W}} 50,000-190,000 \mathrm{Da}$ ) was dissolved in a $\mathrm{pH} 2$ solution of $\mathrm{HCl}$ at a final concentration of $10 \mathrm{mg} / \mathrm{mL}$. After the chitosan was completely dissolved, the $\mathrm{pH}$ was raised to 4.5 by adding $\mathrm{NaOH}$. Then phloretic acid, NHS and EDC were added to the chitosan solution at 7, 1.2,3.9 $\mathrm{mg} / \mathrm{mL}$ respectively. Finally, fluorescein was added to a final concentration of $0.25 \mathrm{mg} / \mathrm{mL}$. Both the reactions were incubated at room temperature for 16 to 20 hours with vigorous stirring and then precipitated dropwise into $80 \%$ ethanol aqueous solutions. The alginate was then washed with $80 \%$ ethanol and the final product dissolved in water before being lyophilized. Chitosan was then washed with $80 \%$ ethanol and then acetone. The final product was dissolved in an acidic solution at $\mathrm{pH}$ 2. After dissolution of the modified chitosan, the $\mathrm{pH}$ was raised to 5 by adding $\mathrm{NaOH}$ before being lyophilized. The success of the conjugations was confirmed through ${ }^{1} \mathrm{H}-\mathrm{NMR}$ (Figure S1). 
Amplification and cloning of the Wild-type GOx gene. The GOx wild type gene was amplified from the genome of Aspergillus niger strain 4247 (LGC Standards) using the primers F1 (5'GCATACGGATCCATGCAGACTCTCCTTGTGAGCTCGC-3') R1 and (5'GCATACCTCGAGTCACTGCATGGAAGCATAATCTTCC-3'), and cloned using BamHI and XhoI restriction sites into the yeast plasmid pYD1 for protein display (gift from Dane Wittrup, Addgene plasmid $\# 73447)^{34}$. After sequence confirmation, the plasmid pYD1-GOx was transformed into Saccharomyces cerevisiae EBY100 following a typical lithium acetate transformation ${ }^{35}$ procedure and selecting the positive colonies on SD agar 2\% (w/v) glucose plates lacking tryptophan (-Trp). Resulting colonies were cultivated in liquid SD -TRP liquid medium with $2 \%$ glucose for 24 hours at $30^{\circ} \mathrm{C}$ with continuous shaking at $200 \mathrm{rpm}$. Protein expression and display was then induced by transferring the culture to a fresh liquid medium lacking tryptophan containing $0.2 \%(\mathrm{w} / \mathrm{v})$ glucose and $1.8 \%(\mathrm{w} / \mathrm{v})$ galactose, and shaking for 24 hours at $30^{\circ} \mathrm{C}$.

Amplex Red enzymatic assay. Yeast cells displaying Glucose Oxidase (GOx) were used to perform an Amplex Red enzymatic assay in order to test for the functionality of the expressed enzyme. The reaction mixture consisted of $\sim 10^{6}$ yeast cells, $100 \mathrm{mM}$ Glucose, $4.5 \mu \mathrm{M}$ HRP and $10 \mu \mathrm{M}$ Amplex Red in 50mM of Phosphate Buffer (pH 7.4). The fluorescence was read at $590 \mathrm{~nm}$ every $1 \mathrm{~min}$ for $10 \mathrm{~min}$ (Figure S2).

GOx antibody labelling. The expression and display of GOx was confirmed by antibody labelling. $\sim 2 \times 10^{6}$ induced yeast cells were washed with $1 \mathrm{~mL}$ PBS containing $0.1 \%$ BSA and then resuspended and incubated at room temperature for 30 min with 1/200 dilution of the primary anti-Xpress antibody (stock concentration of $1.2 \mathrm{mg} / \mathrm{mL}$ ). After incubation, the cells were washed with $1 \mathrm{~mL}$ of ice-cold PBS $+0.1 \%$ BSA and then resuspended in ice cold buffer containing 1/200 dilution of the goat anti mouse IgG secondary antibody (stock concentration $2 \mathrm{mg} / \mathrm{mL}$ ) conjugated with Alexa Fluor 555. After 20 min incubation on ice, the cells were pelleted, washed with cold buffer and resuspended just before flow cytometry. As a negative control, the same yeast cells carrying the plasmid pYD1-GOx wild type were treated only with the secondary antibody conjugated with Alexa Fluor 555.

Cell encapsulation in fluorescent alginate and chitosan. After induction of protein expression, yeast cells displaying GOx were washed with $50 \mathrm{mM}$ sodium phosphate buffer $\mathrm{pH} 7.4$ and resuspended in the same buffer at a final $\mathrm{OD}_{600}$ of 0.2 . Glucose, HRP and the modified alginate were added to the cell sample at final concentrations of $100 \mathrm{mM}, 4.5 \mu \mathrm{M}$, and $0.125 \%(\mathrm{w} / \mathrm{v})$, respectively. The reaction was gently mixed and incubated at room temperature. After $10 \mathrm{~min}$, four volumes of $50 \mathrm{mM}$ sodium phosphate buffer $\mathrm{pH} 7.4$ were added and the samples were analyzed through flow cytometry or used for single cell sorting. Cell encapsulation in chitosan was performed at the exactly same conditions as for the alginate but replacing the sodium phosphate buffer ( $\mathrm{pH} 7.4$ ) with $50 \mathrm{mM}$ MES buffer at $\mathrm{pH}$. When used, mCherry was added to the encapsulation reaction mixture at a final concentration of $4.5 \mu \mathrm{M}$. SEM imaging was performed by first adhering the cells to a coverglass coated with concanavalin, followed by exposure of the coverglass to hydrogel reagents for 10 minutes. Encapsulated cell samples adhered to the coverglass were then fixed in 
glutaraldehyde dried with acetone, and covered with an evaporated thin gold layer prior to SEM imaging using an FEI Versa3D microscope.

Flow cytometry, FACS and downstream analysis. All the single and double stained yeast cells were analyzed with the Attune NxT (Thermo Fisher Scientific) flow cytometer equipped with a $488 \mathrm{~nm}$ and a 561 $\mathrm{nm}$ laser. Yeast cells were sorted using a MoFLo XDP cell sorter from Beckman Coulter equipped with 488 $\mathrm{nm}$ and $561 \mathrm{~nm}$ lasers, and with a $100 \mu \mathrm{m}$ nozzle. Prior to encapsulation and sorting, the yeast cells were washed and stained with Propidium Iodide (final concentration of $4 \mu \mathrm{g} / \mathrm{mL}$ ). The cells positive for the encapsulation reaction and negative for the staining with Propidium Iodide were sorted in single cell mode.

Genotype enrichment by cytoprotection against enzymatic lysis. A mixture of yeast cells containing less than $10 \%$ pGAL-GOx genotype positive cells mixed together with $90 \%$ cells carrying an empty pYD1 plasmid was used to perform a standard cell encapsulation reaction in fluorescent alginate. After cell encapsulation, Zymolyase was added to the reaction mix to a final concentration of $300 \mathrm{U} / \mathrm{ml}$ together with 1 $\mathrm{mM}$ Dithiothreitol (DTT). The reaction was incubated at $35^{\circ} \mathrm{C}$ with shaking at $1000 \mathrm{rpm}$ for 60 minutes. The cells were then transferred to a -Trp glucose liquid medium and grown for 40 hours before being used for single cell sorting onto -Trp agar plates containing 2\% Galactose. After 48 hours, colonies derived from single cell sorted events were assayed for the expression of GOx through an ABTS top agar assay. Glucose (333 mM), ABTS $(7 \mathrm{mM})$ and HRP $(2 \mathrm{U} / \mathrm{ml})$ were mixed with $2 \%$ agar solution and poured on the plate containing the sorted colonies. After 2 to 5 minutes, green halos started to appear above the colonies expressing and displaying the GOx on the cell wall. As a negative control the same yeast population was processed in parallel but without treatment with the lytic enzymes mixture.

Genotype enrichment by size-based filtration. A yeast population containing less than $10 \%$ pGAL-Gox genotypic positive cells was used to perform a standard cell encapsulation reaction in fluorescent alginate. After encapsulation the sample was filtered through polycarbonate membranes with $10 \mu \mathrm{m}$ pores sizes (Whatman) by applying vacuum. Afterwards the membrane was washed three times with $50 \mathrm{mM}$ sodium phosphate buffer at $\mathrm{pH}$ 7.4. Finally the encapsulated cells retained by the filter were recovered by rinsing the the membrane with sodium phosphate buffer ( $\mathrm{pH} 7.4)$ and analyzed with flow cytometry.

pH-responsive chitosan capsules. Multiple samples of yeast cells displaying GOx were washed with 50 $\mathrm{mM}$ MES buffer $\mathrm{pH} 6$ and resuspended in the same buffer at a final $\mathrm{OD}_{600}$ of 0.2. Glucose, HRP and the fluorescent modified chitosan were added to the cells at final concentrations of $100 \mathrm{mM}, 4.5 \mu \mathrm{M}$, and $0.125 \%(\mathrm{w} / \mathrm{v})$, respectively. The reactions were gently mixed and incubated at room temperature. After 20 min, different samples were diluted respectively with four volumes of $50 \mathrm{mM}$ MES buffer $\mathrm{pH} 6,50 \mathrm{mM}$ phosphate buffer $\mathrm{pH} 7.4$ or $50 \mathrm{mM}$ phosphate buffer $\mathrm{pH} 8.2$ to stop the encapsulation reaction. The $\mathrm{pH}$ of each sample was measured and if needed corrected to final $\mathrm{pH}$ values of 6,7 or 8 . The size of the capsules at each $\mathrm{pH}$ was analysed through microscopy by measuring the diameter of multiple randomly picked cellhydrogel units ( $\mathrm{n}>25$ for each $\mathrm{pH}$ value). 


\section{Results and Discussion}

Our reaction system relies on an enzymatic cascade involving glucose oxidase (GOx) and horseradish peroxidase (HRP) to cross-link phenol groups grafted onto various macromonomer species. GOx is a highly glycosylated homodimeric flavoprotein, $160 \mathrm{kDa}$ in size that catalyzes the oxidation of $\beta-\mathrm{D}$ glucose to D-gluconolactone and hydrogen peroxide using molecular oxygen as an electron acceptor ${ }^{36}$. Recently we demonstrated the use of GOx in combination with Fenton's reagent for quantifying enzyme activity based on fluorescent hydrogel formation 37,38 . In the current system, GOx and HRP worked in tandem as a bi-enzymatic initiation system for polymerization of phenolated macromonomers ${ }^{39-42}$.

To synthesize enzyme-crosslinkable species, macromonomers of alginate and chitosan were modified with phenol and fluorescein groups using carbodiimide activation chemistry. Sodium alginate was conjugated with tyramine and aminofluorescein ${ }^{33,43}$ (Scheme 1A), and chitosan was coupled with fluorescein and phloretic acid ${ }^{44,45}$ (Scheme 1B). Following extensive washing and lyophilization, the presence of the aromatic groups of phenol and fluorescein moieties was confirmed using proton nuclear magnetic resonance ( ${ }^{1} \mathrm{H}-\mathrm{NMR}$ ) spectroscopy (Figure S1). We tested the ability of the GOx/HRP cascade to cross-link phenolated monomers in free solution (i.e., without cells) by combining $10 \mathrm{mg} / \mathrm{mL}$ of modified alginate or chitosan macromonomers with $0.5 \mu \mathrm{M}$ GOx and $4.5 \mu \mathrm{M}$ HRP in sodium phosphate buffer (pH 7.4). Upon addition of $100 \mathrm{mM}$ D-glucose, the solution rapidly gelled within a few seconds. Negative controls lacking the HRP or GOx remained liquid. These observations confirmed that the modified macromonomers could be rapidly cross-linked through the GOx/HRP cascade.

We sought to adapt the enzyme-mediated polymerization system to modify, visualize, and isolate cells containing specific genes amidst genetically heterogeneous cell populations based purely on physical properties of the hydrogel capsules. In order to connect the hydrogel polymerization with the genotype of a specific cell line, we incorporated GOx into a eukaryotic cellular display system, and tested the ability of cells carrying the GOx gene to auto-encapsulate in hydrogel shells. HRP, phenolated fluorescent macromonomers, and glucose were presented in the medium to GOx-displaying cells (Figure 1) to initiate the encapsulation reaction. To express GOx on the cell wall, a gene encoding Aspergillus niger GOx was cloned in frame with the yeast a-agglutinin subunit $2(\mathrm{Aga} 2 \mathrm{p})^{46}$ to create an artificial protein display construct.

Translocation and anchoring of Aga2p-GOx to a-agglutinin subunit 1 (Aga1p) on the cell wall were verified by immunostaining with Alexa Fluor 555-conjugated antibodies against a protein tag located between Aga2p and GOx in the fusion construct. Using analytical flow cytometry, we observed an increase in fluorescence for a major fraction of the cell population $(\sim 60 \%)$, indicating successful display of the enzyme (Figure 2A, i). The activity of the displayed enzyme was tested using a coupled HRP/Amplex red assay, which confirmed GOx activity and therefore successful homodimerization of GOx on the cell wall (Figure S2). 
Cells displaying functional GOx homodimers were next used to develop the cell encapsulation system. $2 \times 10^{6}$ yeast cells $/ \mathrm{mL}$ displaying GOx were suspended in a solution of $100 \mathrm{mM}$ glucose, $4.5 \mu \mathrm{M}$ HRP, and $0.125 \%(\mathrm{w} / \mathrm{v})$ of phenolated alginate. After $10 \mathrm{~min}$. reaction at room temperature, the samples were analyzed and a significant percentage $(\sim 60 \%)$ of cells corresponding to the same percentage successfully stained for GOx exhibited strong green fluorescence derived from fluorescein, consistent with the formation of fluorescent hydrogel shells around the cells (Figure 2A, ii). We further tested the encapsulation procedure with a yeast population displaying GOx that had previously been stained with Alexa Fluor 555 for the display of GOx on the cell wall. As shown in Figure 2A, iii, after incubation in the reaction mixture a majority of the cell population prestained with red fluorescent antibodies targeting GOx also gained green fluorescence signal due to the formation of the fluorescent hydrogel. This result confirmed that cells expressing GOx were the same cells in the mixture capable of auto-encapsulating in fluorescent hydrogels.

To further prove the specificity of the cellular encapsulation system, we tested the encapsulation procedure using different cell reference mixtures containing diluted amounts of GOx-positive cells at a fixed total number of cells. After encapsulation, the flow cytometry plots showed a precise correspondence between the percentage of GOx positive cells present in the cell mixtures and the number of fluorescein stained cells detected after encapsulation (Figure 2B). Moreover, 25 gated cells sorted in single cell mode from a mixture containing 10\% GOx positive events were re-cultured and singularly tested for GOx activity. All of them tested positive for functional GOx, indicating the fidelity of the encapsulation process despite the presence of a limited number of positive events in the starting sample (Figure S3).

We characterized the morphology of the alginate hydrogel capsules using confocal fluorescence microscopy. A well-defined conformal fluorescent alginate hydrogel was observed surrounding the cells (Figure 3A). The orthogonal views show a homogenous distribution of hydrogel surrounding the dark cell mass in the center. A 3D spatial representation is presented in Figure S4. We confirmed that only single cells and not clusters of multiple cells were being encapsulated using widefield and confocal fluorescence microscopy on a large number of encapsulated cell populations obtained through multiple independent experiments. We consistently observed dark spots (single cells) or budding yeast inside the green fluorescent capsules (Figure S5). The single cell nature of the encapsulation reaction was also confirmed using analytical flow cytometry plots of the scattered pulse height vs. scattered pulse width per event, which distinguished between single cells, budding yeast cells, and cell aggregates (Figure S6).

We investigated the kinetics of gel formation by measuring the thickness of the hydrogel shells using fluorescence microscopy and image analysis following incubation of the reaction for various lengths of time. Figure 3B shows that the alginate shells grew rapidly during the first few minutes, reaching a particle diameter of $\sim 30 \mu \mathrm{m}$ including the entrapped cell. This rapid growth was followed by a plateau phase wherein extended incubation times ( $>10 \mathrm{~min}$ ) did not increase the size of the hydrogel shells. This is an advantageous feature of the system that we attribute to auto-inhibition of the reaction. Auto-inhibition is expected upon 
The artificial alginate layer formed around cells displaying functional GOx also served as an enhanced safeguard against cytotoxic agents. The cytoprotective function of the alginate shell was tested through incubation of a heterogeneous population of yeasts containing less than $10 \%$ of GOx positive encapsulated cells with Zymolyase, which is a mixture of lytic enzymes that digests the yeast cell wall leading to osmotic lysis and cell death. After incubation with $300 \mathrm{U} / \mathrm{ml}$ of Zymolyase for 60 minutes, the cell mixture containing 10\% GOX-positive cells was recultivated and sorted in single cell mode onto agar plates. The clonal colonies were then assayed for GOx activity and the fraction of GOx-positive colonies was found to be $100 \%$. This result indicated that the hydrogel capsules conferred resistance to enzymatic lysis to GOxpositive cells (Figure 5A) with zero background level survival. Although the hydrogel capsule is porous and allows the diffusion of small nutrients and molecules, it acts as diffusion barrier for large macromolecules such as proteins and enzymes and therefore inhibited Zymolyase enzymes from attaching to and digesting the cell wall. The porosity of the alginate gel layer and as a consequence the efficacy of the diffusion barrier can be tuned by varying the concentration of crosslinkable moieties in the conjugation reaction. 
The alginate layer formed around the cells carrying the pGAL-GOx genes provided new physical properties to the cells, a feature we refer to as an artificial phenotype. We exploited the significant increase in apparent cell size that occurs upon enzymatic encapsulation in a filtration process to separate encapsulated cells from non-encapsulated cells (Figure 5B). Heterogeneous populations of yeast cells where $10 \%$ of cells carried the pGAL-GOx gene were first encapsulated in fluorescent alginate and then filtered through $10 \mu \mathrm{m}$ pores size filters. As expected, the bare yeast cells ( 2 to $5 \mu \mathrm{m}$ in diameter) could easily pass through the filter and were discarded in the flow through. Encapsulated yeast cells (20 to $30 \mu \mathrm{m}$ in diameter), however, were retained on the filter and could be recovered for further analysis. Figure 5B shows a micrograph of green fluorescent hydrogel capsules adhered onto the polycarbonate filter membrane. The dark spots in the image are the membrane pores. Following this filtration procedure, the yeast cell population encapsulated in fluorescent hydrogel and positive for the pGAL-GOx gene was enriched from $10 \%$ to $95 \%$ within two filtration steps, each requiring only 2 minutes of processing time (Figure 5C). Both the cell survival and filtration procedures have relevant applications for the enrichment of genetic libraries in directed evolution experiments, or in automated genomics applications where a specific genetically tagged cell line can be separated from genetically diverse mixtures, thus providing a rapid, high-throughput, scalable and affordable alternative to cell sorting.

As an alternative to alginate, we further investigated the use of the polysaccharide chitosan for encapsulation of cells. Chitosan has been used in biomedical applications and drug delivery systems due to its biocompatibility and its mechanical and chemical properties ${ }^{48}$. Dissolution of chitosan in aqueous buffers is achieved only at acidic $\mathrm{pH} \leq 6$, when the amino groups of the polymer are protonated. This solubility switch in aqueous environments causes the swelling and deswelling of the polymer based on the $\mathrm{pH}^{49}$. The $\mathrm{pH}$ sensitivity of chitosan hydration presented an interesting feature for cell encapsulation applications by providing a tool to tune the permeability and elasticity of the polymer and regulate the accessibility to the encapsulated cells. Chitosan with phenol and fluorescein moieties (Scheme 1B) was used for cell encapsulation using a slightly modified protocol at $\mathrm{pH}$ 6. Phenolated chitosan showed similar behavior to the modified alginate, however, the chitosan shells showed higher stability and less tendency to form nonspecific interactions with filter membranes as compared to alginate. Chitosan capsules were found to be less prone to aggregation and the gel capsules did not break under mechanical stress such as during centrifugation and filtration.

The $\mathrm{pH}$ sensitivity of the chitosan capsules was investigated by varying the $\mathrm{pH}$ of the solution containing encapsulated cells from 6 to 8 and observing the behavior of the hydrogel capsules using fluorescence microscopy. We note that yeast cells are stable and remain viable in a $\mathrm{pH}$ range of 6 to 8 , therefore tuning the capsules diameter with $\mathrm{pH}$ is compatible with in vivo processing and propagation of the cells $^{50}$. Yeast cells encapsulated with fluorescent chitosan at $\mathrm{pH} 6$ presented a well-defined and water swollen shell that was not visible in bright field mode but was clearly visible in fluorescence mode (Fig 6A upper panels). The chitosan capsule was not visible at $\mathrm{pH} 6$ using bright field imaging because the 
refractive index difference between the hydrogel and the surrounding water was too low, and the swollen hydrogel did not scatter sufficient light. Nonetheless, at $\mathrm{pH}$ 6, a diffuse bright water-swollen hydrogel was clearly observable using fluorescence imaging (Figure 6A, upper right panel). By resuspending the same cell sample in basic buffer ( $\mathrm{pH}$ 8), we observed a radical reduction in the size of the gel layer around the cells. At $\mathrm{pH} 8$, the chitosan capsules were clearly visible in both bright field and fluorescence modes (Figure 6A lower panels). The insolubility of the chitosan at $\mathrm{pH} 8$ trigged dehydration and collapse of the capsule onto the yeast cell. The pH-tunable solubility of the chitosan is based on protonation/deprotonation of the amino groups which have a $\mathrm{pKa}$ of $\sim 6.5$. This mechanism allowed for visualization of the chitosan hydrogel layer surrounding the cells even bright field mode (Figure 6A, bottom left panel), eliminating the requirement of fluorescence microscopy to visualize the capsules. The fluorescence imaging at $\mathrm{pH} 8$ also indicated a highly condensed hydrogel with much smaller diameter (Figure 6A, bottom right panel). This pH-responsive mechanism for visualization is beneficial because high energy light sources can cause cell damage under prolonged exposure. A movie of the chitosan coat shrinking upon increasing the $\mathrm{pH}$ is provided in the supplementary materials (Supplementary Movie 2). To correlate the size of the capsules with the solution $\mathrm{pH}$, we incubated a population of chitosan encapsulated cells at increasing $\mathrm{pH}$ from 6 to 8 and imaged them using fluorescence microscopy. We found a clear decrease and narrowing of the size distribution from $\sim 80$ $\mu \mathrm{m}$ to $\sim 15 \mu \mathrm{m}$ upon increased the $\mathrm{pH}$ from 6 to 8 . Collapse of the gel at $\mathrm{pH} 8$ is expected to alter the elasticity and porosity of the gel. We expect the ability to finely control physical features of the artificial capsules can be relevant for different biochemical separation processes and controlled release of proteins from the cells in many biotechnological and medical applications.

\section{Conclusions}

Cell encapsulation systems are by now well established. Typically single-cell encapsulation systems rely on addition of initiating species from the external media. The novelty of the approach reported here is based on three aspects. Firstly, the initiating enzyme is synthesized by the cell itself and displayed on the cell wall, a process that originates from a plasmid-derived copy of the gene encoding the initiating GOx enzyme. This means that the presence of the hydrogel capsule qualifies as an artificial cell phenotype, providing a novel genotype-phenotype linkage. Secondly, the hydrogel shells reported here are robust and confer significantly altered physical properties to the cells that make them easily processable in bulk operations. We demonstrated isolation of the encapsulated cells using size-based filtration as well as immunity to enzymatic and osmotic lysis mixtures. And thirdly, chitosan has been used as a tissue engineering scaffold but was this far not utilized for enzyme-mediated single-cell encapsulation. The $\mathrm{pH}$-responsiveness of chitosan capsules can provide $\mathrm{pH}$-tunable cell phenotypes.

Our system as described is compatible with yeast cells with ease of genetic manipulation and protein display, however it is also generalizable to other cell types. Such an approach of displaying initiating enzymes on the cell surface to initiate cell encapsulation reactions could be readily adapted to $E$. coli or 
mammalian cell display systems in the future. Such a system is also adaptable to other classes of bioinitiators, proteins and enzymes that can trigger radical polymerization providing a valuable tool for visualization, protection and isolation of genetically high value cells from heterogeneous cell populations. This new artificial eukaryotic cellular phenotype provides advantages for cell selection or evolution campaigns and points towards the development of synthetic extracellular matrices or artificial biofilms that can be programmed at the genetic level. This exciting area of bottom-up cell-directed materials synthesis is one of the areas where we expect our presented reaction system to find significant applications.

\section{Acknowledgments}

We thank Ivan Urosev for help with ${ }^{1} \mathrm{H}-\mathrm{NMR}$ measurements and data analysis. We thank Fabian Rudolf and Florian Seebeck for helpful discussions. We are grateful to Martin Oeggerli (Micronaut) for assistance with SEM imaging. We thank Nico Strohmeyer and Daniel Müller for assistance with further imaging experiments. This work was funded by a Human Frontier Science Program (HFSP) Young Investigator Grant (RGY80/2015), by Society in Science - The Branco Weiss Fellowship (ETH Zurich), and by the National Center for Competence in Research Molecular Systems Engineering (NCCR-MSE).

\section{Supporting Information}

Supporting Figures (S1-S9) available. S1: ${ }^{1} \mathrm{H}-\mathrm{NMR}$ spectrum of macromonomers; S2: GOx amplex red assay on cell surface; S3: ABTS top agar assay; S4: 3D confocal fluorescence image of encapsulated cell; S5: Additional fluorescence microscopy imaging of cells; S6: Flow cytometry plots of non-encapsulated vs. encapsulated cells; S7: Trapping of extracellular fluorescent protein inside gel; S8: Growth curve of encapsulated cells.

\section{Figure Captions}

Scheme 1. Modification of macromonomers with phenols and fluorophores. (A) Reaction scheme for production of alginate macromonomer. (B) Reaction scheme for preparation of chitosan macromonomer.

Figure 1. Overview of genetically encoded hydrogel encapsulation system for single cells. Scheme depicting gene induction and yeast display of GOx homodimer, followed by enzyme-mediated cross-linking of phenolated fluorescent monomers into a conformal hydrogel surrounding the cell. Modified monomers carry fluorescein and phenol moieties are depicted as a green circle and yellow star, respectively. 
Figure 2. Flow cytometry analysis of cells displaying GOx and enzymatically encapsulated in fluorescent hydrogel. (A) Flow cytometry analysis of (i) a yeast population displaying GOx and stained with anti-Xpress antibody; (ii) yeast enzymatically encapsulated in fluorescent alginate hydrogel; and (iii) doubly stained yeast population confirming surface display of GOx (Alexa fluor 555-labelled anti-Xpress antibody) and encapsulation in fluorescent hydrogel (fluorescein-modified alginate). (B) Cell reference mixtures used to test the fidelity of the encapsulation process. Decreasing amounts of GOx positive cells in the starting mixtures were detected through analytical flow cytometry following the encapsulation reaction. An example of a flow cytometry plot with the gate used for the analysis is shown on the right.

Figure 3. Fluorescence imaging and sizing of alginate capsules. (A) Confocal fluorescence microscopy images of yeast cells individually encapsulated in a conformal alginate shell following 10 minute reaction. Fluorescein incorporated in alginate capsules allowed direct visualization of the hydrogel shells in $X$, $Y$, and $Z$ projections using confocal fluorescence microscopy. (B) Hydrogel particle diameters (including cell diameter) were measured at different reaction times $(n=10$ cells for each time point) by analyzing confocal fluorescence images.

Figure 4. (A) SEM micrograph showing an encapsulated budding yeast adjacent to an unencapsulated budding yeast cell. (B) SEM image of singly encapsulated yeast cells. Shell diameters are smaller under vacuum SEM imaging conditions.

Figure 5. Strategies for pGAL-GOx genotype enrichment. (A) Immunity to enzymatic lysis. Genetically heterogeneous yeast cell populations containing 10\% cells carrying the pGAL-GOx gene were encapsulated in fluorescent alginate and treated with lytic enzymes. The fraction of pGAL-GOx genotype-positive colonies was quantified before and after enzymatic lysis. The recultivated population contained only $p G A L-G O x$ positive cells which were protected from enzymatic lysis by the hydrogel layer. (B) Size exclusion by filtration. Encapsulated yeast cells in fluorescent alginate (green) were retained by the polycarbonate filter with $10 \mu \mathrm{m}$ pores (dark spots). Scale bar indicates $100 \mu \mathrm{m}$. (C) A yeast cell population containing 10\% cells carrying the pGAL-GOx gene was encapsulated in alginate and processed by filtration through a 10 um pore filter membrane. The majority of non-encapsulated cells was removed, resulting in 95\% pGAL-GOx positive cells retained on the filter.

Figure 6. pH-responsive chitosan capsules. (A, top) Single budding yeast cell encapsulated in a fluorescent chitosan capsule at pH 6. The chitosan hydrogel is swollen and invisible in bright field. (A, bottom) Single budding yeast cell encapsulated in fluorescent chitosan at pH 8. The polymer shell is collapsed around the cell. At pH 8, the chitosan layer around the cells is also visible in bright field mode as indicated by the red arrows. Scale bars indicate $10 \mu \mathrm{m}$. (B) Size distribution of chitosan-encapsulated single cells following resuspension in aqueous buffers with increasing pH from 6 to 8. Average capsules diameters and standard deviations: $67.6 \pm 20.5 \mu \mathrm{m}$ at $\mathrm{pH} 6,27.8 \pm 12.8 \mu \mathrm{m}$ at $\mathrm{pH} 7$, and $13.2 \pm 4 \mu \mathrm{m}$ at $\mathrm{pH} 8$ ( $\mathrm{n}>25$ cells for each pH). 


\section{References}

(1) Wörsdörfer, B.; Woycechowsky, K. J.; Hilvert, D. Directed Evolution of a Protein Container. Science 2011, 331, 589-592.

(2) Fischlechner, M.; Schaerli, Y.; Mohamed, M. F.; Patil, S.; Abell, C.; Hollfelder, F. Evolution of Enzyme Catalysts Caged in Biomimetic Gel-Shell Beads. Nat. Chem. 2014, 6, 791-796.

(3) Sjostrom, S. L.; Bai, Y.; Huang, M.; Liu, Z.; Nielsen, J.; Joensson, H. N.; Andersson Svahn, H. HighThroughput Screening for Industrial Enzyme Production Hosts by Droplet Microfluidics. Lab Chip 2014, 14, 806-813.

(4) Tawfik, D. S.; Griffiths, A. D. Man-Made Cell-like Compartments for Molecular Evolution. Nat. Biotechnol. 1998, 16, 652-656.

(5) Mao, A. S.; Shin, J.-W.; Utech, S.; Wang, H.; Uzun, O.; Li, W.; Cooper, M.; Hu, Y.; Zhang, L.; Weitz, D. A.; et al. Deterministic Encapsulation of Single Cells in Thin Tunable Microgels for Niche Modelling and Therapeutic Delivery. Nat. Mater. 2017, 16, 236-243.

(6) Theberge, A. B.; Courtois, F.; Schaerli, Y.; Fischlechner, M.; Abell, C.; Hollfelder, F.; Huck, W. T. S. Microdroplets in Microfluidics: An Evolving Platform for Discoveries in Chemistry and Biology. Angew. Chem. Int. Ed Engl. 2010, 49, 5846-5868.

(7) Niu, J.; Lunn, D. J.; Pusuluri, A.; Yoo, J. I.; O’Malley, M. A.; Mitragotri, S.; Soh, H. T.; Hawker, C. J. Engineering Live Cell Surfaces with Functional Polymers via Cytocompatible Controlled Radical Polymerization. Nat. Chem. 2017, 9, 537-545.

(8) Romero, G.; Lilly, J. J.; Abraham, N. S.; Shin, H. Y.; Balasubramaniam, V.; Izumi, T.; Berron, B. J. Protective Polymer Coatings for High-Throughput, High-Purity Cellular Isolation. ACS Appl. Mater. Interfaces 2015, 7, 17598-17602.

(9) Shubin, A. D.; Felong, T. J.; Schutrum, B. E.; Joe, D. S. L.; Ovitt, C. E.; Benoit, D. S. W. Encapsulation of Primary Salivary Gland Cells in Enzymatically Degradable Poly(ethylene Glycol) Hydrogels Promotes Acinar Cell Characteristics. Acta Biomater. 2017, 50, 437-449.

(10) Cahall, C. F.; Lilly, J. L.; Hirschowitz, E. A.; Berron, B. J. A Quantitative Perspective on Surface Marker Selection for the Isolation of Functional Tumor Cells. Breast Cancer 2015, 1-11.

(11) Karoubi, G.; Ormiston, M. L.; Stewart, D. J.; Courtman, D. W. Single-Cell Hydrogel Encapsulation for Enhanced Survival of Human Marrow Stromal Cells. Biomaterials 2009, 30, 5445-5455.

(12) Lim, F.; Sun, A. M. Microencapsulated Islets as Bioartificial Endocrine Pancreas. Science 1980, 210 , 908-910.

(13) Uludag, H.; De Vos, P.; Tresco, P. A. Technology of Mammalian Cell Encapsulation. Adv. Drug Deliv. Rev. 2000, 42, 29-64.

(14) Shoichet, M. S.; Li, R. H.; White, M. L.; Winn, S. R. Stability of Hydrogels Used in Cell Encapsulation: An in Vitro Comparison of Alginate and Agarose. Biotechnol. Bioeng. 1996, 50, 374-381.

(15) Wu, P.-J.; Lilly, J. L.; Arreaza, R.; Berron, B. J. Hydrogel Patches on Live Cells through SurfaceMediated Polymerization. Langmuir 2017, 33, 6778-6784.

(16) Lilly, J. L.; Berron, B. J. The Role of Surface Receptor Density in Surface-Initiated Polymerizations for Cancer Cell Isolation. Langmuir 2016, 32, 5681-5689.

(17) Avens, H. J.; Berron, B. J.; May, A. M.; Voigt, K. R.; Seedorf, G. J.; Balasubramaniam, V.; Bowman, C. N. Sensitive Immunofluorescent Staining of Cells via Generation of Fluorescent Nanoscale Polymer Films in Response to Biorecognition. J. Histochem. Cytochem. 2011, 59, 76-87.

(18) Sakai, S.; Taya, M. On-Cell Surface Cross-Linking of Polymer Molecules by Horseradish Peroxidase Anchored to Cell Membrane for Individual Cell Encapsulation in Hydrogel Sheath. ACS Macro Lett. 2014, 3, 972-975.

(19) Yang, J.; Li, J.; Wang, X.; Li, X.; Kawazoe, N.; Chen, G. Single Mammalian Cell Encapsulation by in Situ Polymerization. J. Mater. Chem. B Mater. Biol. Med. 2016, 4, 7662-7668.

(20) Kim, J. Y.; Lee, B. S.; Choi, J.; Kim, B. J.; Choi, J. Y.; Kang, S. M.; Yang, S. H.; Choi, I. S. Cytocompatible Polymer Grafting from Individual Living Cells by Atom-Transfer Radical 
Polymerization. Angew. Chem. Int. Ed Engl. 2016, 55, 15306-15309.

(21) Rossi, N. A. A.; Constantinescu, I.; Brooks, D. E.; Scott, M. D.; Kizhakkedathu, J. N. Enhanced Cell Surface Polymer Grafting in Concentrated and Nonreactive Aqueous Polymer Solutions. J. Am. Chem. Soc. 2010, 132, 3423-3430.

(22) Nguyen, K. T.; West, J. L. Photopolymerizable Hydrogels for Tissue Engineering Applications. Biomaterials 2002, 23, 4307-4314.

(23) Malinowska, K. H.; Nash, M. A. Enzyme- and Affinity Biomolecule-Mediated Polymerization Systems for Biological Signal Amplification and Cell Screening. Curr. Opin. Biotechnol. 2016, 39, 68-75.

(24) Kobayashi, S.; Uyama, H.; Kimura, S. Enzymatic Polymerization. Chem. Rev. 2001, 101, 3793-3818.

(25) Shoda, S.-I.; Uyama, H.; Kadokawa, J.-I.; Kimura, S.; Kobayashi, S. Enzymes as Green Catalysts for Precision Macromolecular Synthesis. Chem. Rev. 2016, 116, 2307-2413.

(26) Sakai, S.; Komatani, K.; Taya, M. Glucose-Triggered Co-Enzymatic Hydrogelation of Aqueous Polymer Solutions. RSC Adv. 2012, 2, 1502-1507.

(27) Nakahata, M.; Gantumur, E.; Furuno, K.; Sakai, S.; Taya, M. Versatility of Hydrogelation by DualEnzymatic Reactions with Oxidases and Peroxidase. Biochem. Eng. J. 2018, 131, 1-8.

(28) Kim, B. J.; Park, T.; Moon, H. C.; Park, S.-Y.; Hong, D.; Ko, E. H.; Kim, J. Y.; Hong, J. W.; Han, S. W.; Kim, Y.-G.; et al. Cytoprotective Alginate/polydopamine Core/shell Microcapsules in Microbial Encapsulation. Angew. Chem. Int. Ed Engl. 2014, 53, 14443-14446.

(29) Park, J. H.; Hong, D.; Lee, J.; Choi, I. S. Cell-in-Shell Hybrids: Chemical Nanoencapsulation of Individual Cells. Acc. Chem. Res. 2016, 49, 792-800.

(30) Kim, B. J.; Cho, H.; Park, J. H.; Mano, J. F.; Choi, I. S. Strategic Advances in Formation of Cell-inShell Structures: From Syntheses to Applications. Adv. Mater. 2018, 30, e1706063.

(31) Wang, B.; Liu, P.; Jiang, W.; Pan, H.; Xu, X.; Tang, R. Yeast Cells with an Artificial Mineral Shell: Protection and Modification of Living Cells by Biomimetic Mineralization. Angew. Chem. Int. Ed Engl. 2008, 47, 3560-3564.

(32) Pitzler, C.; Wirtz, G.; Vojcic, L.; Hiltl, S.; Böker, A.; Martinez, R.; Schwaneberg, U. A Fluorescent Hydrogel-Based Flow Cytometry High-Throughput Screening Platform for Hydrolytic Enzymes. Chem. Biol. 2014, 21, 1733-1742.

(33) Sakai, S.; Kawakami, K. Synthesis and Characterization of Both Ionically and Enzymatically CrossLinkable Alginate. Acta Biomater. 2007, 3, 495-501.

(34) Kieke, M. C.; Cho, B. K.; Boder, E. T.; Kranz, D. M.; Wittrup, K. D. Isolation of Anti-T Cell Receptor scFv Mutants by Yeast Surface Display. Protein Eng. 1997, 10, 1303-1310.

(35) Gietz, R. D.; Woods, R. A. Transformation of Yeast by Lithium Acetate/single-Stranded Carrier DNA/polyethylene Glycol Method. Methods Enzymol. 2002, 350, 87-96.

(36) Swoboda, B. E. P.; Massey, V. Purification and Properties of the Glucose Oxidase from Aspergillus Niger. J. Biol. Chem. 1965, 240, 2209-2215.

(37) Malinowska, K. H.; Verdorfer, T.; Meinhold, A.; Milles, L. F.; Funk, V.; Gaub, H. E.; Nash, M. A. Redox-Initiated Hydrogel System for Detection and Real-Time Imaging of Cellulolytic Enzyme Activity. ChemSusChem 2014, 7, 2825-2831.

(38) Malinowska, K. H.; Rind, T.; Verdorfer, T.; Gaub, H. E.; Nash, M. A. Quantifying Synergy, Thermostability, and Targeting of Cellulolytic Enzymes and Cellulosomes with Polymerization-Based Amplification. Anal. Chem. 2015, 87, 7133-7140.

(39) Zavada, S. R.; Battsengel, T.; Scott, T. F. Radical-Mediated Enzymatic Polymerizations. Int. J. Mol. Sci. 2016, 17, 195.

(40) Uyama, H.; Kurioka, H.; Kobayashi, S. Novel Bienzymatic Catalysis System for Oxidative Polymerization of Phenols. Polym. J. 1997, 29, 190-192.

(41) Sigg, S. J.; Seidi, F.; Renggli, K.; Silva, T. B.; Kali, G.; Bruns, N. Horseradish Peroxidase as a Catalyst for Atom Transfer Radical Polymerization. Macromol. Rapid Commun. 2011, 32, 1710-1715.

(42) Sakai, S.; Tsumura, M.; Inoue, M.; Koga, Y.; Fukano, K.; Taya, M. Polyvinyl Alcohol-Based Hydrogel Dressing Gellable on-Wound via a Co-Enzymatic Reaction Triggered by Glucose in the Wound Exudate. J. Mater. Chem. B Mater. Biol. Med. 2013, 1, 5067-5075.

(43) Liu, Y.; Sakai, S.; Kawa, S.; Taya, M. Identification of Hydrogen Peroxide-Secreting Cells by Cytocompatible Coating with a Hydrogel Membrane. Anal. Chem. 2014, 86, 11592-11598.

(44) Jin, R.; Moreira Teixeira, L. S.; Dijkstra, P. J.; Karperien, M.; van Blitterswijk, C. A.; Zhong, Z. Y.; Feijen, J. Injectable Chitosan-Based Hydrogels for Cartilage Tissue Engineering. Biomaterials 2009, $30,2544-2551$. 
(45) de Campos, A. M.; Diebold, Y.; Carvalho, E. L. S.; Sánchez, A.; Alonso, M. J. Chitosan Nanoparticles as New Ocular Drug Delivery Systems: In Vitro Stability, in Vivo Fate, and Cellular Toxicity. Pharm. Res. 2004, 21, 803-810.

(46) Wang, H.; Lang, Q.; Li, L.; Liang, B.; Tang, X.; Kong, L.; Mascini, M.; Liu, A. Yeast Surface Displaying Glucose Oxidase as Whole-Cell Biocatalyst: Construction, Characterization, and Its Electrochemical Glucose Sensing Application. Anal. Chem. 2013, 85, 6107-6112.

(47) Pryor, W. A. Oxy-Radicals and Related Species: Their Formation, Lifetimes, and Reactions. Annu. Rev. Physiol. 1986, 48, 657-667.

(48) Bernkop-Schnürch, A.; Dünnhaupt, S. Chitosan-Based Drug Delivery Systems. Eur. J. Pharm. Biopharm. 2012, 81, 463-469.

(49) Szymańska, E.; Winnicka, K. Stability of Chitosan-a Challenge for Pharmaceutical and Biomedical Applications. Mar. Drugs 2015, 13, 1819-1846.

(50) Imai, T.; Ohno, T. The Relationship between Viability and Intracellular $\mathrm{pH}$ in the Yeast Saccharomyces Cerevisiae. Appl. Environ. Microbiol. 1995, 61, 3604-3608. 


\section{TOC Graphic}

\section{Cytoprotective genotype-phenotype linkage}

Genetic

program Displayed

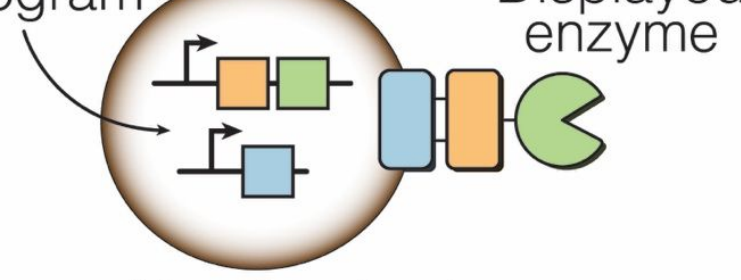

Fluorescent

Yeast cell

Enzyme-mediated polymerization

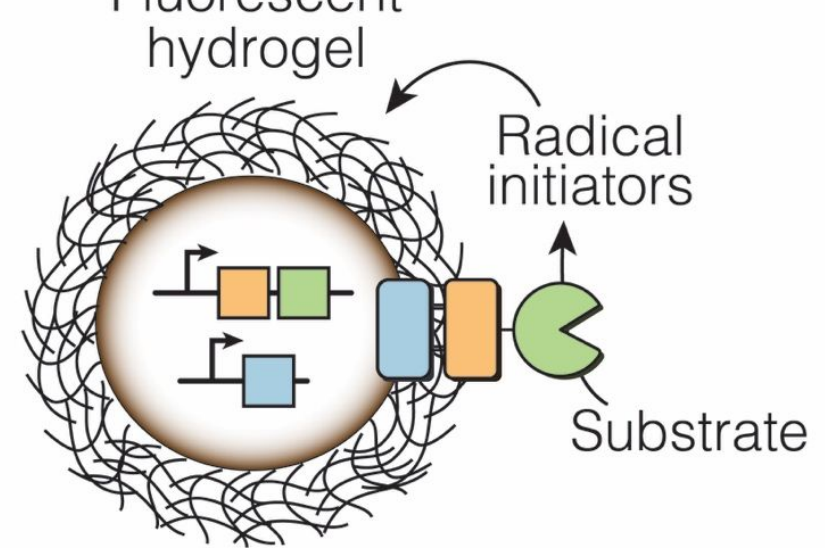

